\title{
Children's Serial Recall Errors: Implications for Theories of Short-Term Memory Development
}

\author{
Teresa McCormack, Gordon D. A. Brown, and Janet I. Vousden \\ University of Warwick, Coventry, United Kingdom
}

and

\author{
Richard N. A. Henson
}

Institute of Cognitive Neuroscience, University College London, London, United Kingdom

\begin{abstract}
Three experiments examined developmental changes in serial recall of lists of 6 letters, with errors classified as movements, omissions, intrusions, or repetitions. In Experiments 1 and 2, developmental differences between groups of children aged from 7 to 11 years and adults were found in the pattern of serial recall errors. The errors of older participants were more likely to be movements than were those of younger participants, who made more intrusions and omissions. The number of repetition errors did not change with age, and this finding is interpreted in terms of a developmentally invariant postoutput response inhibition process. This interpretation was supported by the findings of Experiment 3, which measured levels of response inhibition in 7-, 9-, and 11-year-olds by comparing recall of lists with and without repeated items. Response inhibition remained developmentally invariant, although older children showed greater response facilitation (improved correct recall of adjacent repeated items). Group differences in the patterns of other errors are accounted for in terms of developmental changes in levels of output forgetting and changes in the efficiency of temporal encoding processes. (๑) 2000 Academic Press

Key Words: short-term memory; rehearsal; inhibition; speed; distinctiveness; development.
\end{abstract}

The serial recall task is the most widely used measure of adult verbal shortterm memory (STM). In this task, participants are presented with a series of items, often letters, which they must remember in the correct order. Recently,

This research was supported by grants from the MRC (G9608199) and the ESRC (R000236216). We are grateful to Stuart Brown for collecting the data for Experiment 3, and to Elizabeth Maylor for advice on data analysis. We are also grateful to Nelson Cowan and two anonymous reviewers for their comments on an earlier version of this paper.

Address correspondence and reprint requests to Teresa McCormack, Department of Psychology, University of Warwick, Coventry CV4 7AL, United Kingdom. E-mail: T.McCormack@ warwick.ac.uk. 
much research on adult STM has focused on examining the detailed patterns of errors made over different serial positions in such tasks. This examination of error patterns under various task conditions has proved useful in adjudicating between different models of adult verbal STM (e.g., Brown, Preece, \& Hulme, 2000; Burgess \& Hitch, 1999; Henson, 1998b). Our aim in the present paper is to use a similar method to examine the development of STM.

Errors made on serial recall tasks are commonly placed in one of three categories (see Henson, 1996, for further subdivisions). Two of these categories can be thought of as item errors: An intrusion error occurs when an item from outside the original presentation set is given as a response, and an omission error occurs when no response is given for a particular serial position. An order or movement error occurs when a list item is recalled in an incorrect serial position. Task manipulations may affect particular error types differentially. For example, phonological similarity tends to affect movements and intrusions rather than omissions (see Henson, 1998b, for other examples).

From a developmental perspective, differential effects of this kind suggest that developmental changes in serial recall performance may not be accompanied by equivalent changes in all error types (Maylor, Vousden, \& Brown, 1999). Furthermore, as we discuss below, some models of STM development make predictions regarding the particular changes in error patterns expected to be associated with the development of serial recall. However, the majority of STM studies with children have not examined such error patterns in detail. The aim of the current paper is to explore the predictions that current theoretical approaches to STM development make in relation to error patterns, and to provide a detailed empirical examination of such patterns.

\section{Rehearsal-Based Accounts of STM Development}

Many studies of verbal STM in children have involved tasks that require serial recall (e.g., Hulme, Silvester, Smith, \& Muir, 1986; Pickering, Gathercole, \& Peaker, 1998; Roodenrys, Hulme, \& Brown, 1993). The general aim of many such studies has been to examine whether changes in rehearsal processes are the principle cause of the development of verbal STM (e.g., Henry, 1991; Hitch, Halliday, Dodd, \& Littler, 1989; Hitch, Halliday, Schaafstal, \& Heffernan, 1991; Hulme \& Tordoff, 1989; for reviews see Cowan \& Kail, 1996; Gathercole \& Hitch, 1993; Henry \& Miller, 1993). However, detailed predictions regarding developmental changes in specific patterns of errors in serial recall tasks have typically not been generated from rehearsal-based accounts. As they stand, such accounts simply predict improvements in overall levels of performance, without specifying the pattern of error changes expected to accompany STM development. Without a well-specified account of the rehearsal process, and a description of how it functions in conjunction with serial recall mechanisms, such predictions are unlikely to be forthcoming (Brown \& Hulme, 1995). 


\section{Output Effects and STM Development}

It is widely accepted that simple rehearsal-based accounts need to consider additional developmental factors in the light of findings that suggest that age changes in memory span may be related to output processes. For example, effects of word length or articulation rate may actually reflect speed of output rather than the involvement of rehearsal processes (Cowan et al., 1992; Cowan, Wood, Nugent, \& Treisman, 1997; Henry, 1991; see also Brown \& Hulme, 1995; Neath \& Nairne, 1995, for demonstrations that word-length effects can be modeled without assuming rehearsal processes). Further, levels of performance may be closely related to the speed of memory search processes operating between successive item retrievals (Cowan \& Kail, 1996; Cowan et al., 1998).

The general claim is that changes in speed of output contribute to developmental improvements in memory span, since the rate of recall determines the amount of forgetting. If this is correct, then we would expect to see particular developmental changes in error patterns in serial recall tasks. Specifically, younger children should tend to omit items at later serial positions, since forgetting during output will have a more marked effect on these items.

\section{Effects of Inhibition}

The inhibition hypothesis assumes that changes in inhibitory processes contribute to age differences in memory capacity, since such processes affect whether irrelevant information intrudes into or remains in STM (Harnishfeger \& Bjorklund, 1993; Hasher, Stoltzfus, Zacks, \& Rympa, 1991; Wilson \& Kipp, 1998). Further, a variety of studies have indicated that inhibitory processes develop across childhood, and may play a role in memory development (e.g., Brainerd, 1995; Dempster, 1992, 1993; Diamond, 1991; Harnishfeger \& Bjorklund, 1993; Harnishfeger \& Pope, 1996; Tipper, Bourque, Anderson, \& Brehaut, 1989; Wilson \& Kipp, 1998).

Inhibition is a broad construct. For present purposes, we take Harnishfeger's (1995, p. 188) definition of inhibition as an "active suppression process." In the context of many models of verbal serial recall this receives a very specific interpretation, because it has become widely accepted that the inhibitory process of postoutput response suppression plays a crucial role in many kinds of serially ordered behavior (Brown et al., 2000; Hartley \& Houghton, 1996; Henson, 1998a; Houghton, 1990; Lewandowsky, 1999; Vousden \& Brown, 1998). Specifically, it is assumed that once an item has been recalled, its representation is then suppressed and its level of activation gradually recovers (e.g., Burgess \& Hitch, 1999; Houghton, 1994; Lewandowsky \& Farrell, in press; Page \& Norris, 1998; Vousden \& Brown, 1998). Thus, recently recalled items are temporarily less available for retrieval until such inhibition wears off. It should be emphasized that this inhibitory process is normally assumed to wear off rapidly (after around two or three subsequent item recalls), and is distinct from any processes 
that may be involved in preventing interference from previous lists or in excluding task-irrelevant information.

There are two main reasons for assuming such a process operates in serial recall. First, it provides a parsimonious explanation of how serial recall proceeds after the most highly activated item has been chosen in a winner-take-all selection process. For example, Houghton (1994) has argued that postoutput inhibition is necessary in order to "control or dampen dominant activity patterns" (p. 150) in systems such as those involved in sequential behavior. Second, the assumption is consistent with aspects of serial recall data. Repetition errors, which occur when an item is erroneously repeated during recall, are actually relatively infrequent in adult recall, particularly when items are not phonologically similar and when none of the original lists contains repetitions. Further, if an item is repeated, this tends to be at a long lag after the first recall of the item (Conrad, 1965). More direct evidence for such inhibitory processes comes from studies in which some of the presentation lists include repeated items. In such tasks, there is a tendency for participants to fail to recall the repeated elements even when they are aware that the lists contain repetitions-the Ranschburg effect (Henson, 1998a; Jahnke, 1969; Jahnke \& Bower, 1986). This effect suggests that the repeated item is suppressed following retrieval of its first occurrence (see Henson, 1998a, for further discussion of the role of inhibition in the Ranschburg effect).

In the light of recent developmental claims regarding inhibitory processes, it is plausible that changes in response suppression play a role in verbal STM development. This suggestion can be explored by examining developmental changes in repetition errors. First, if such inhibitory processes improve in efficiency with age, then we would expect developmental decreases in the number of erroneous repetitions at small lags. Second, we would expect to see developmental changes in the probability of omitting repeated items when lists do contain repetitions (i.e., in the size of the Ranschburg effect). These predictions are tested experimentally below.

\section{Temporal Distinctiveness}

The final possibility that we consider is that there might be developmental changes in the temporal distinctiveness of items in memory. According to temporal distinctiveness approaches to memory, temporal information plays a crucial role in memory organization and retrieval (Glenberg, 1987; Glenberg \& Swanson, 1986). The central claim of such approaches is that items have values along an internally represented temporal dimension (see also Lee \& Estes, 1981; Nairne, 1992), and that the distinctiveness of items' values on this dimension determines their probability of retrieval (Neath, 1993a, 1993b; Neath \& Crowder, 1990, 1996).

Temporal distinctiveness models have not themselves been directly applied to the development of serial recall. However, a central component of several recent 
computationally explicit models of verbal STM is the idea that the serial order of items is encoded with reference to states of a dynamic, time-varying learningcontext signal of some kind (e.g., Brown et al., 2000; Burgess \& Hitch, 1992, 1999). Such models can be seen as mechanism-level instantiations of the temporal distinctiveness approach, and varying the quality of the context signal in such models can be thought of as varying the temporal distinctiveness of items (Brown, Vousden, McCormack, \& Hulme, 1999; see also Glenberg, 1987). Such changes in the efficiency of the temporal encoding process may be an important factor in the development of STM. A number of existing studies have already demonstrated developmental changes in recall of temporal information in STM tasks in which item memory is not required (Healy, Cunningham, Gesi, Till, \& Bourne, 1991; see Berch, 1979, for review of earlier studies).

Could developmental changes on serial recall tasks be related to changes in the temporal encoding process? Elsewhere, we have shown that varying temporal distinctiveness will affect performance in several ways (Brown et al., 1999; Maylor et al., 1999). The numbers of both item and order errors at all serial positions varies with changes in the effectiveness (distinctiveness) of the available serial retrieval cues. Further, there are also changes in the probability that when movement errors are made, items are placed close to their true serial position (i.e., changes in the steepness of movement gradients). We examine this specific prediction below.

\section{The Current Study}

In the experiments which follow, we conducted a detailed examination of the error patterns made by children and adults on a serial recall task. Although a few studies have reported error data (in particular, Pickering et al., 1998, report such data in detail), their findings are difficult to interpret. Typically, spoken recall of auditorily or visually presented sequences of items has been used to assess children's serial recall. However, there are inherent ambiguities in the scoring method employed in this task; for example, although a list ABCD could be recalled as either $\mathrm{AB}-\mathrm{D}$ or $\mathrm{ABD}$ - (i.e., omitting $\mathrm{C}$ ), standard spoken recall does not make it possible to classify such responses differently.

We used a written serial recall procedure which enabled us to classify most errors unambiguously. In order to permit comparison of error movement gradients and error proportions across different age groups, the study used lists of the same length for each age group (if different list lengths are employed, the number of opportunities for different error types varies, making comparisons difficult). A wide range of the life span was studied (from 7 years to adulthood), although it was not possible to use our serial recall procedure with children younger than 7 .

\section{EXPERIMENT 1}

\section{Method}

Participants. The participants were 20 adults (range $=18-50$ years) and 20 children in each of three age groups: 7-year-olds, 9-year-olds, 11-year-olds. 
Children who participated in this study were predominantly Caucasian and of middle class. Each child was given a colored sticker of his or her choice for participation in the study; the adults received no payment or course credit.

Materials and design. A set of six phonologically confusable letters (B, D, G, $\mathrm{P}, \mathrm{T}, \mathrm{V})$ and a set of six nonconfusable letters $(\mathrm{H}, \mathrm{K}, \mathrm{M}, \mathrm{Q}, \mathrm{R}, \mathrm{Y})$ were used. Each stimulus was a $2.5-\mathrm{cm}$ uppercase letter printed on a 10 by $7-\mathrm{cm}$ card. Each set of six stimuli was used to construct five lists, with the order of letters randomized for each list, subject to the constraint that the letters did not form well-known acronyms. A further two lists of nonconfusable letters were constructed for use as practice lists. Thus, following practice trials, participants received 10 list presentations in total (5 confusable, 5 nonconfusable), with the order of confusable and nonconfusable lists counterbalanced. Responses were made in writing on a response sheet containing 12 lines of six boxes, one box for each serial position.

Procedure. The experiment was conducted in a single session of approximately $20 \mathrm{~min}$. Participants were individually tested in a quiet environment. Each participant was initially familiarized with the 12 stimuli and required to name the letters. It was then explained that they would be shown lists of six letters, and that letters would be presented one at a time. Participants were instructed to try to remember each list of letters, and to recall lists in writing on their response sheets. It was emphasized that it was important to recall the letters in the correct order, and that recall was to take place in a left-to-right manner, with one letter to be placed in each box. Compliance with these instructions was monitored by the experimenter. Participants were encouraged to guess if they were unsure of a letter, and if they could not guess to put a line in the appropriate box. They were shown a written example on their response sheet as a demonstration. Two practice lists were given to ensure that participants understood the instructions, followed by the 10 test lists.

\section{Results and Discussion}

Preliminary analysis revealed that the effects of interest were qualitatively similar for confusable and nonconfusable lists, although performance was significantly better on nonconfusable than on confusable lists $[F(1,76)=40.12$, $M S E=0.01, p<.01 ;$ this difference did not interact with age, $F<1]$. Therefore, performance is collapsed over type of list in the following analyses, in part because there were insufficient numbers of errors to permit detailed analyses of each list type independently.

Figure 1 shows the proportion of correct responses as a function of serial position and age. It can be seen that performance appears to improve with age, and that all groups show standard primacy effects. Some groups also appear to show a degree of recency over the last one or two serial positions. An analysis of variance (ANOVA) with a between-subjects factor of age and a withinsubjects factor of serial position examined correct performance. The main effect 


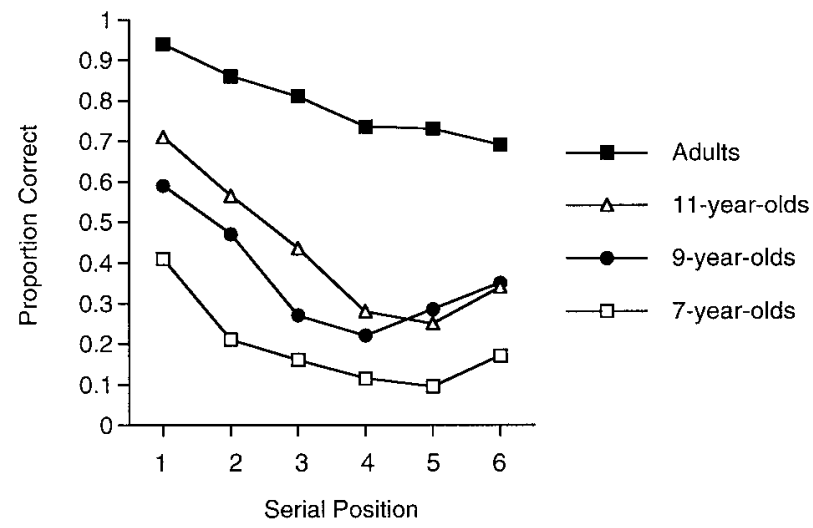

FIG. 1. Proportion of correct responses in Experiment 1 as a function of serial position and age.

of age was significant $[F(3,76)=75.36, M S E=0.10, p<.01]$, as was the main effect of serial position $[F(5,380)=45.21, M S E=0.03, p<.01]$. The interaction between serial position and age was also significant $[F(15,380)=$ $2.11, M S E=0.03, p<.01]$. Further analyses therefore examined whether the size of the primacy effect (as given by the difference between proportion correct at the first and second serial positions) and the recency effect (as given by the difference between the fifth and sixth serial positions) changed with age. However, neither effect changed significantly with age $[F(3,76)=1.67, M S E=$ $0.03, p=.18$, for the primacy effect; $F(3,76)=2.01, M S E=0.04, p=$ .12 , for the recency effect].

All errors were classified as movements, omissions, intrusions, or repetitions according to the following criteria. An omission error was recorded whenever one of the recall boxes was left blank. Thus, if the sequence ABCDEF was presented, recall as $\mathrm{ABC}-\mathrm{EF}$ involved one omission error. Note, therefore, that the number of omissions refers here to the number of response boxes in which no item was recalled; it does not refer to the number of presented list items that were omitted at recall. A movement error was recorded whenever a list item was recalled in the incorrect position within the list. Distance of the movement was also noted. Thus, if the sequence ABCDEF was presented, recall as ABC-DF involved one omission (nothing is recalled in output position 4) and one movement (item $\mathrm{D}$ is recalled in position 5, one away from its target position). Note that by this scoring scheme, an exchange between two items was scored as two movement errors. It should also be noted that any errors involving the repetition of items were not included in the movement errors: Such errors were classified as repetition errors. A repetition error occurred if an item correctly recalled elsewhere in the list was also erroneously repeated in another serial position (e.g., if $\mathrm{ABCDEF}$ was recalled as $\mathrm{EBCDEF}$, the first occurrence of $\mathrm{E}$ was scored as a repetition error). In addition, if an item was recalled twice with neither occur- 


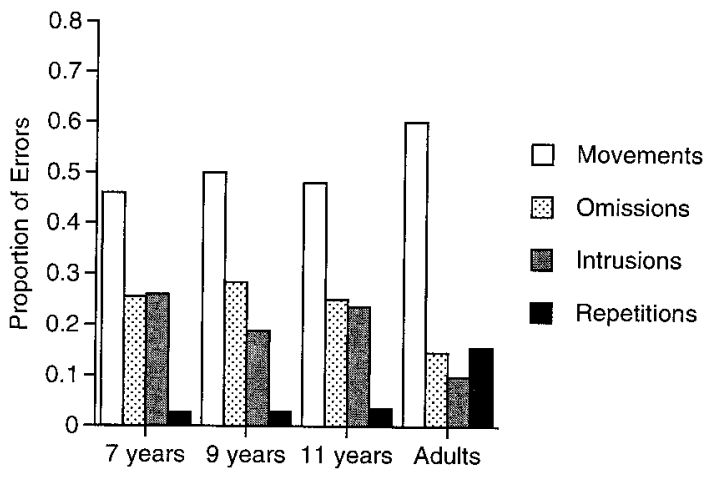

Age Group

FIG. 2. Proportion of errors in Experiment 1 that are of each type as a function of age.

rence in the correct position, this was scored as one repetition error and one movement error (e.g., ABCDEF recalled as EBEACF was scored as one repetition error and one movement error). Lastly, an intrusion error was recorded whenever an extralist item was recalled (e.g., recall as ABCDKF).

For each age group, Fig. 2 shows the number of each of these types of errors expressed as a proportion of all errors and collapsed over all serial positions (due to the small numbers of errors of some types made by older age groups, it was not possible to analyze how errors were distributed over serial positions). It can be seen that although movement errors predominate for each age group, the ratio of movement errors to omission and intrusion errors appears be greater in the adult group. Further, the proportions of errors that were repetitions appear to increase with age. Four ANOVAs examined the effect of age on the proportions of each error type. One adult who made no errors was excluded from these analyses. The effect of age on the proportion of movement errors just failed to reach significance $[F(3,75)=2.55, M S E=0.03, p=.06]$, and was also not significant for omission proportions $[F(3,75)=1.54, M S E=0.05, p=.21]$. There was a significant effect of age on intrusion proportions $[F(3,75)=3.33$, $M S E=0.3, p<.05]$, with a smaller proportion of adult errors being intrusions, and on repetition proportions $[F(3,75)=4.99, M S E=0.02, p<.01]$, with the proportion of errors that were repetitions increasing with age.

Movement errors were examined further in terms of the distance away from their true positions that moved items were placed. Plots of movement gradients are shown in Fig. 3; these are the number of movement errors at each distance expressed as a proportion of all movement errors. It can be seen that the steepness of these gradients increases with age: Older participants appear to be more likely to place items close to their true serial positions. Five separate ANOVAs examined the effect of age on the proportions of movement errors at each distance (the data from three adults who did not make any movement errors are 

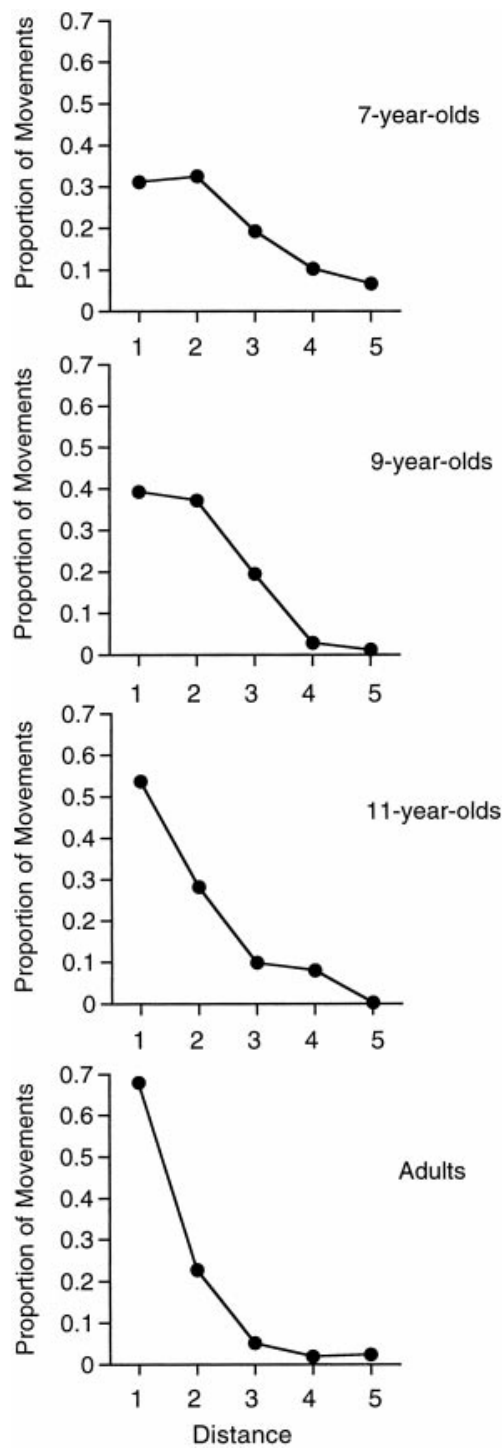

FIG. 3. Movement gradients in Experiment 1 as a function of age.

excluded). There was a significant main effect of age for each distance $[F(3$, $73)>3.02, p<.05$, for all analyses], with older groups making more movements at a distance of 1 , but fewer at distances of 3,4 , and 5 .

In summary, not only did overall performance change, but there were agerelated changes in the nature of the errors made by participants. With age, there was an increase in the probability that incorrectly placed items were placed close 
to their true serial positions. That is, there were significant improvements in the accuracy of order memory. Further, the errors made by children were more likely to be intrusion errors than those made by adults, who tended to make more movement errors. Lastly, errors made by adults and older children were also more likely to be repetition errors than those made by younger participants. Thus, there was no evidence that the response suppression process improves in efficiency with age. However, it was not possible to examine the prediction of output forgetting accounts, that there should be an age-related decrease in the number of omission errors at later serial positions, since there were too few errors for a meaningful analysis by serial position. We therefore postpone discussion until after the results of further experiments have been presented.

\section{EXPERIMENT 2}

Experiment 2 used a procedure similar to that of Experiment 1 to examine developmental changes in serial recall. However, there were a number of methodological changes. First, all lists were composed of confusable items, with the aim of producing a sufficient number of errors to enable analysis by serial position. As described below, such analyses can be carried out as a function of both input and output serial position in order to distinguish between encoding effects and output effects. Second, computerized presentation was used to ensure that presentation time was standardized, and participants were instructed to read the letters aloud as they were presented to ensure that they paid attention to the task and did not miss any items. Third, the vocabulary ability of all children was assessed so that relationships between performance and verbal ability could be examined.

\section{Method}

Participants. Sixty-eight children aged between 7 and 11 years from two primary schools participated in the study. These were subsequently divided into groups on the basis of their verbal ability, as described below. Children who participated in this study were predominantly Caucasian and of low-middle class. There was also an adult group, composed of 27 undergraduates attending the University of Warwick. The undergraduates received credit in an introductory psychology course for their participation.

Materials and design. All children received a vocabulary test in addition to the memory task. This was the Long Form of the British Picture Vocabulary Scale (Dunn, Dunn, Whetton, \& Pintilie, 1982), a test of receptive vocabulary comprehension that has been standardized on a British population of children.

The letters used for the serial recall task were six phonologically confusable consonants (B, D, G, P, T, V). From this letter set, 24 six-item lists were constructed, with the constraints that the letters were never presented in their alphabetical order, that each letter was approximately equally probable in each position, and that the frequency of adjacent pairs of letters was approximately 
uniform. For test trials, 16 lists were sampled from this set of 24 lists for each participant. Two other lists from the set were used as practice lists; a further three four-item practice lists were also generated using the same letters.

Letters were presented at a rate of one per second on the screen of a portable computer, with each list being initiated by the experimenter pressing the space bar on the keyboard. The letters were in uppercase 36-point Helvetica font. Participants made written responses on a response sheet which contained 16 rows of six boxes (one box for each serial position), with additional rows for practice trials.

Procedure. Children were individually tested in a quiet room in their schools, and received the serial recall task and the BPVS in either one or two sessions depending on the time taken to complete the BPVS. Testing sessions lasted approximately 20-25 min. Adults were tested individually in a laboratory, and were given the serial recall task as one of a number of cognitive tasks that they completed in an hour-long session. The serial recall task was introduced to participants by explaining to them that they would see lists of six letters appearing on the screen one after another. They were told to pronounce the names of the letters aloud as they appeared (to ensure that they paid attention to the list and to counter any group differences in the tendency to name spontaneously). They were shown the response sheet, and told that for each list there was a row of six boxes, one box for each letter. They were instructed to write down each list of letters in the correct order as soon as the list had finished, working from left to right. It was emphasized that participants should try to guess if they could not remember the appropriate letter for a box. However, if they really were unable to guess, they were told to put a line through the box, with the experimenter demonstrating this response. The practice trials began with the participants observing the experimenter recall a list of six letters in the appropriate way. They were encouraged to monitor the experimenter's performance to see whether she recalled the list correctly. Participants were then given two four-item lists, followed by one practice six-item list. Before beginning the test trials, they were reminded to complete each row of their response sheet from left to right, and to read the letter names aloud on every trial. They were also told at this stage that the same six letters that they had encountered during practice trials would be used in every list, although letters would be presented in a different order for every list. They then completed the 16 test trials, with the experimenter monitoring compliance with task instructions. All children were given a short break after 8 trials since many of them found the task tiring; adults completed the 16 trials without a break.

\section{Results}

Preliminary correlational analysis examined the relation between performance (percentage of correct responses), chronological age (CA), and verbal mental age (VMA). The correlation between CA and performance was not significant once 


\section{TABLE 1}

Percentage of Responses of Each Type as a Function of Age

\begin{tabular}{|c|c|c|c|c|c|c|c|c|c|c|c|c|}
\hline \multirow[b]{3}{*}{ Group } & \multicolumn{6}{|c|}{ Input } & \multicolumn{6}{|c|}{ Output } \\
\hline & \multicolumn{2}{|c|}{$\begin{array}{c}\% \\
\text { Correct }\end{array}$} & \multicolumn{2}{|c|}{$\begin{array}{c}\% \\
\text { Omitted }\end{array}$} & \multicolumn{2}{|c|}{$\begin{array}{c}\% \\
\text { Moved }\end{array}$} & \multicolumn{2}{|c|}{$\begin{array}{c}\% \\
\text { Omissions }\end{array}$} & \multicolumn{2}{|c|}{$\begin{array}{c}\% \\
\text { Intrusions }\end{array}$} & \multicolumn{2}{|c|}{$\begin{array}{c}\% \\
\text { Repetitions }\end{array}$} \\
\hline & $M$ & $S E$ & $M$ & $S E$ & $M$ & $S E$ & $M$ & $S E$ & $M$ & $S E$ & $M$ & $S E$ \\
\hline Adults & 55.3 & 2.3 & 5.3 & 2.0 & 39.4 & 2.6 & 0.5 & 1.3 & 0.2 & 1.2 & 4.6 & 1.0 \\
\hline \multicolumn{13}{|l|}{ VMA } \\
\hline$>11$ years & 40.8 & 2.8 & 12.1 & 2.4 & 47.1 & 3.1 & 3.9 & 1.4 & 3.6 & 1.4 & 4.6 & 1.1 \\
\hline $9-10$ years & 33.1 & 2.6 & 14.8 & 2.3 & 52.1 & 2.9 & 6.1 & 1.4 & 3.7 & 1.3 & 5.0 & 1.1 \\
\hline$<9$ years & 22.7 & 2.3 & 23.0 & 2.0 & 54.3 & 2.5 & 9.9 & 1.2 & 9.7 & 1.2 & 3.4 & 0.9 \\
\hline
\end{tabular}

VMA was partialed out $[r(65)=.17, p=.18]$, but the correlation between VMA and performance remained significant when CA was partialed out $[r(65)=.37, p<.01]$. Comparison of children's CA and VMA revealed that although the mean difference between these ages was 1.34 years, there were 12 children for whom this difference was greater than 2 years. After consideration of these findings, it was decided to divide children up into three groups on the basis of their VMA rather than their CA, with the first group being those children with VMA of less than 9 years $(N=28$, VMA $M=8.00, S E=0.23$; and CA $M=8.03, S E=0.17)$, the second group those with VMA of 9 or 10 years $(N=21$, VMA $M=9.82, S E=0.27$; and CA $M=9.09, S E=0.20)$, and the third group those with VMA of 11 years or greater $(N=19$, VMA $M=$ 13.04, $S E=0.28$; and CA $M=10.72, S E=0.21)$. It should be noted that a pattern of developmental changes similar to that reported below is obtained if children are divided into groups on the basis of CA.

Correct responses by serial position. Table 1 summarizes the overall performance of all age groups, and Fig. 4 shows the mean proportion of items recalled correctly as a function of serial position and age (the distributions of errors are also shown in the figure). Age differences were apparent across all serial positions. There were clear serial position effects, with primacy effects for all groups, and recency effects that appeared to be more marked in the older groups. Performance in the youngest group was poor, and close to floor for some serial positions, although a one-sample $t$ test showed that the overall performance of this group (collapsed across all serial positions) was significantly above chance $[t(27)=3.89, p<.01]$

A two-way ANOVA with a between-subjects factor of age and a withinsubjects factor of serial position examined correct performance. The main effect of age was significant $[F(3,91)=35.01, M S E=3.06, p<.01]$, as was the effect of serial position $[F(5,455)=89.29, M S E=1.33, p<.01]$. Although the interaction between age and serial position failed to reach significance $[F(15$, 

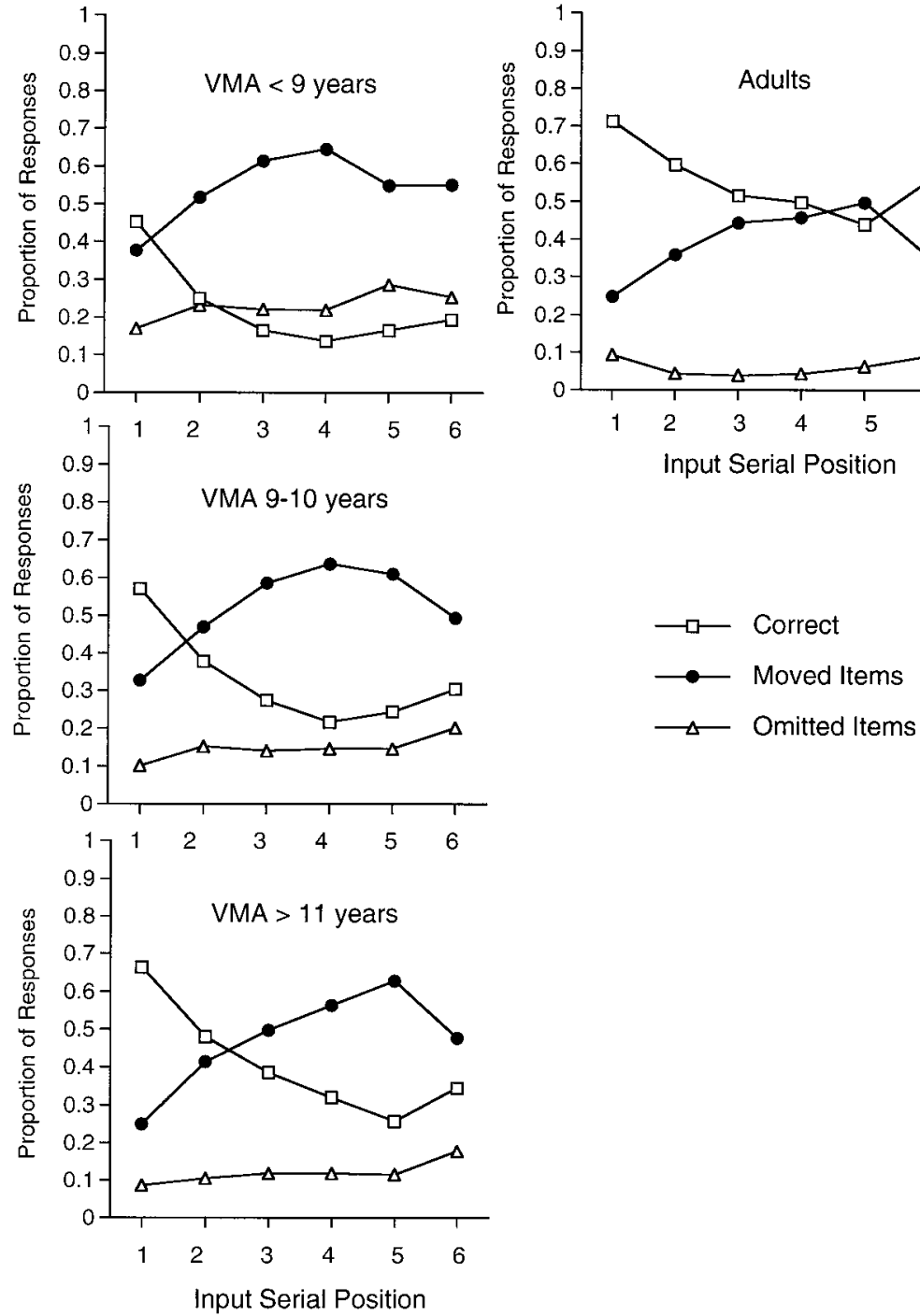

FIG. 4. Proportion of all responses in Experiment 2 that are correct, moved items, and omitted items as a function of input serial position and age.

$455)=1.66, M S E=0.02, p=.06]$, the size of the recency effect seemed to increase with age. However, a one-way ANOVA on the difference between the proportions of correct responses to the fifth and the sixth serial positions found that the effect of age also failed to reach significance $[F(3,91)=2.38, M S E=$ $0.04, p=.08]$. 

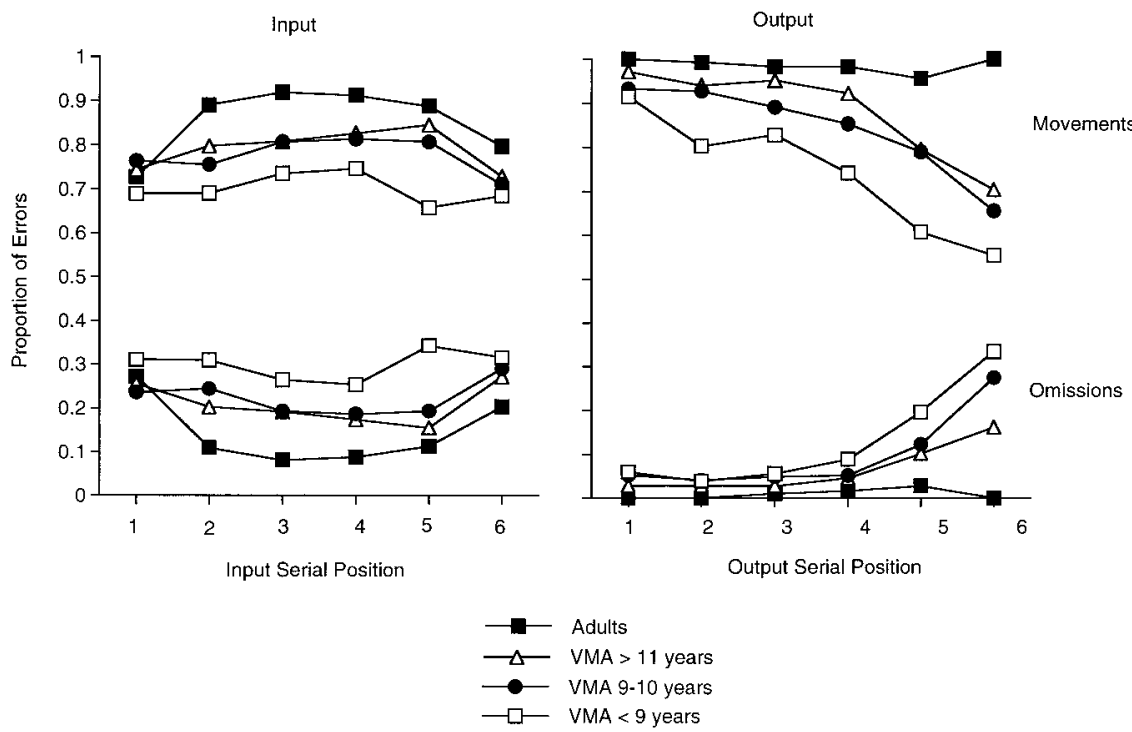

FIG. 5. Proportion of errors in Experiment 1 as a function of age that are (left) moved items and omitted items as a function of input serial position and (right) movement and omission errors as a function of output serial position.

Analysis of errors by input serial position. Errors were initially examined with respect to their original list position at presentation, that is, with respect to input. If an item from the presentation set did not feature in recall, the error was classified as an omitted item. Thus, if a list BTGVPD was recalled without B featuring anywhere in output, this was scored as an omitted item from the first input serial position. If B was recalled, but placed in the wrong serial position, this was classified as a moved item from the first input serial position (regardless of which position B occupied at recall). Inspection of error patterns as a function of input position can be used to examine the role of encoding factors in STM development. For example, if the proportion of omitted items increased at later input serial positions for the younger groups, this would suggest that their encoding of items is more affected by the presentation of previous items in the list (e.g., due to interference or attentional factors).

For each age group, the percentages of responses which were classified as each of these error types are shown in Table 1. It can be seen from the table that the numbers of both moved and omitted items decreased with age. Further, the number of moved relative to omitted items appears to increase with age. In order to examine changes in this ratio, numbers of moved and omitted items were calculated as a proportion of both error types, with the distribution of these proportions across input serial positions shown on the left in Fig. 5. For the purposes of analysis, moved item proportions were collapsed across input serial 
positions 1-3 and serial positions 4-6 (since for some older participants, no errors of a particular type were made at certain serial positions). A two-way ANOVA with a between-subjects factor of age and a within-subjects factor of input position (1-3 versus $4-6)$ on these moved item proportions found a significant main effect of age $[F(3,91)=6.72, M S E=0.05, p<.01]$. The effect of input position was not significant $[F(1,91)=1.70]$, nor was the interaction between age and input position $[F(3,91)=1.33]$. Thus, the proportion of errors that were moved rather than omitted items increased with age, but did not vary significantly with input serial position.

Analysis of errors by output serial position. It is possible to break down errors into further categories by examining responses with respect to output serial position. Such an analysis of how error patterns change over the course of output enables an assessment of the role of output effects in determining performance. As described in Experiment 1, errors with respect to output were classified as omission errors, intrusion errors, movement errors, and repetition errors. The output serial position of each of these errors was also noted, although it was not possible to assign a serial position to many of the errors that involved repetitions: If an item was recalled twice with neither occurrence in the correct position, there was no basis for deciding which of the item occurrences should be thought of as the movement error and which the repetition error. Thus, repetition errors are not included in the following analyses by serial position; analyses of these errors are described separately below.

The percentage of all responses that were classified as each of these errors was calculated for each participant, and the means for each age group are given in Table 1. The right side of Fig. 5 shows the distribution across output serial position of movement errors and omissions errors as a proportion of movement, omission, and intrusion errors (the proportion of intrusion errors is not shown but can be inferred). It can be seen that the relative proportion of movement errors to other error types is greater in older groups, and that this is more marked for later serial positions.

Separate ANOVAs on the numbers of each error type expressed as a proportion of all three errors were carried out, with a between-subjects factor of age and a within-subjects factor of serial position (1-3 versus $4-6)$. There were significant main effects of age on the proportions of all error types $[F(3,91)>6, p<$ .01 , for all three effects]. The proportions of errors which were movements increased with age, whereas the proportions which were intrusions and omissions decreased with age. The main effects of serial position were also significant for all three error types $[F(1,91)>9, p<.01$, for all three effects]. The two-way interaction between serial position and age was not significant for intrusion proportions. However, the two-way interaction was significant for movement proportions $[F(3,91)=6.08, M S E=0.09, p<.01]$, and for omission error proportions $[F(3,91)=7.54, M S E=0.01, p<.01]$. Analysis of simple effects showed that the proportion of errors that were omissions rather than 

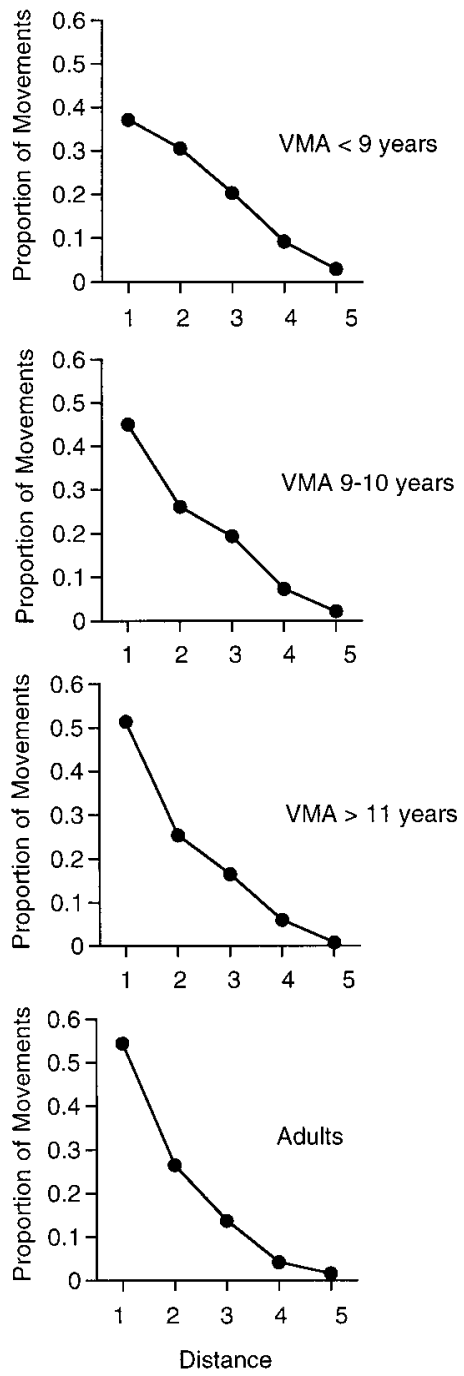

FIG. 6. Movement gradients in Experiment 2 as a function of age.

movements was greater in later serial positions for the groups of children $[F(1$, 91) $>8, p<.01]$ but not for the adults $[F<1]$.

Movement gradients. Figure 6 shows the movement gradients. The steepness of these gradients appears to increase with age, with the majority of movements made by the two older groups being at a distance of one, whereas this was not the case for the younger two groups (although note that there are more opportunities for movement errors to occur over small rather than large 
distances, such that if errors were distributed randomly, $33 \%$ of errors would involve a movement distance of just 1). Five separate one-way ANOVAs examined the effect of age on the proportion of movements at each distance, and there was a significant effect of age for all distances $[F(3,91)>3.4$, $p<.03$, for all comparisons].

Repetition errors. A one-way ANOVA found no significant effect of age on the number of repetition errors $(F<1)$. Further analysis of repetition errors was carried out by distinguishing between anticipations (e.g., BTGVPD recalled as BDGVPD, with the first occurrence of $\mathrm{D}$ being an anticipation), perseverations (e.g., BTGVPD recalled as BTGVPB, with the second occurrence of B the perseveration), or unclassified repetitions (errors in which neither occurrence of a repeated item was in the correct place). Some existing research on patterns of repetition errors in speech has suggested that there are developmental changes in the ratio of anticipations to perseverations, with perseverations being relatively more frequent in the speech of younger children (Dell, Burger, \& Svec, 1997). In our data, unclassified repetitions were the most common type in all groups, and the developmental trend found in speech errors was not apparent [indeed, the adults produced twice as many perseverations ( $M=2.24 \%$ responses) as anticipations $(M=1.12 \%)$, whereas the youngest group produced similar numbers of each of these errors $(M=0.89 \%$ of responses were perseverations and $M=0.75 \%$ were anticipations)]. A two-way ANOVA with a betweensubjects factor of age and a within-subjects factor of number of repetition errors of each type found no significant interaction between age and error type $[F(3$, $91)=1.36, M S E=1.95, p=.26]$.

Although it was not possible to examine the distribution of repetition errors across serial positions, the distance between the first occurrence of an item and its subsequent repetition was calculated. Plots of the mean numbers of repetition errors of each distance expressed as a proportion of all repetitions are shown in Fig. 7. These repetition gradients provide a measure of the time course of the response suppression process, since they indicate how soon after their first retrieval that items tend to become available for recall again (Vousden \& Brown, 1998). It can be seen that for all age groups, small proportions of repetitions were made at short distances, with the proportion of repetitions peaking at a distance of 3. The repetition gradients showed a tendency to increase in sharpness with age, although this tendency was not consistent. To analyze whether there was an effect of age on repetition separation, it was necessary to compare the proportions of repetitions at the smaller distances of 1 and 2 with the proportions made at larger distances of 3,4, and 5. Thirteen participants were excluded from the analysis since they had made no repetitions. An ANOVA on the number of repetitions made by the remaining participants at short distances as a proportion of all repetitions found no significant effect of age $[F(3,78)=1.16, M S E=$ $.12, p=.33]$. Thus, the repetition gradients did not change significantly with age. 

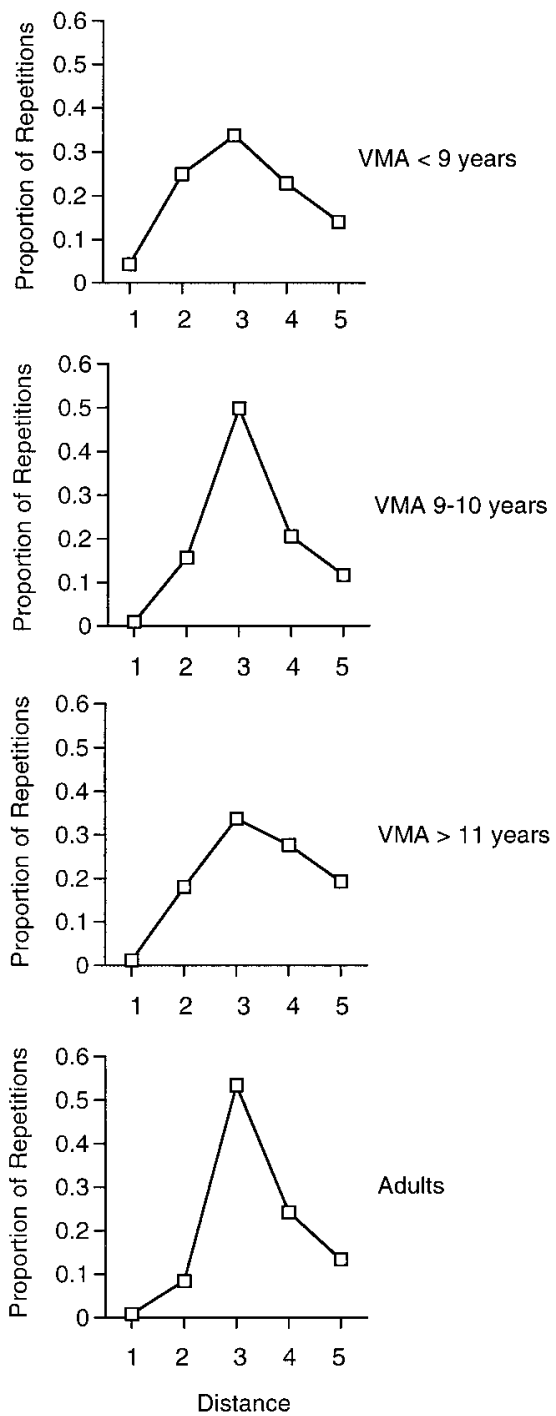

FIG. 7. Repetition gradients in Experiment 2 as a function of age.

\section{Discussion}

In line with previous studies of STM, there were significant developmental improvements in the proportion of items recalled in the correct serial position. Some aspects of performance remained developmentally invariant. First, all groups showed standard serial position curves, with marked primacy effects and moderate recency effects (although there was a nonsignificant tendency for the 
size of the recency effect to increase with age). Recency effects were more marked than in Experiment 1, which is likely to be because participants named items aloud in this experiment, effectively leading to auditory as well as visual presentation (Murray, 1968). Second, as in Experiment 1, movement errors were the predominant error type in all groups, with relatively small numbers of items from the presentation lists being omitted at recall. Third, neither the numbers of repetition errors nor their separation changed significantly with age. Indeed, there was a trend toward fewer repetition errors in the younger groups.

However, there were developmental patterns in other aspects of performance. Consistent with the findings of Experiment 1, movement gradients became significantly steeper with age. Further, there was a developmental effect on the pattern and distribution of errors. With age, the proportion of movement errors relative to omissions and intrusions increased. Analysis of the relative distributions of error types across serial position revealed an interesting difference between the effects of output and input serial position. As recall progressed, the relative proportion of omission to movement errors increased for the children but remained constant for the adults. This suggests that there are developmental differences in levels of forgetting toward the end of a list, which may be due to differences in speed of recall. This finding can be interpreted as an output rather than an encoding effect because there was no developmental effect on the fate of items presented at later versus earlier input serial positions.

As in Experiment 1, there was no evidence of an increase in the efficiency of the response suppression process, as measured by the number of repetition errors. The developmental invariance in the absolute number of repetition errors found in Experiment 2 is surprising given the large age changes found in other types of errors. One possible explanation of this aspect of the error data is that younger children failed to utilize the information that there was a fixed set of list items (see Pickering et al., 1998, for a similar suggestion, although it should be noted that, in the present study, participants were explicitly told that the same items were always used). Such a failure may have made it more likely that young children would have either included a letter outside the presentation set in their recall or made an omission, since they did not realize that responses should be restricted to items from a fixed set. Older participants may have tended to be consistent in limiting their responses to list items, thus making repetition errors rather than omissions and intrusions. If this is correct, then developmental changes in response suppression could have been masked by such age differences in the use of the information that there was a fixed list vocabulary.

Based on these data, the patterns of intrusions, omissions, and repetitions could be due to changes in basic memory processes or to changes in understanding of how lists are composed. However, we note that elderly adults, who would be expected to have no difficulties with this feature of the task, also make more 
intrusions and omissions than young adults (Maylor et al., 1999). In Experiment 3 , we examined the development of response suppression more directly using lists which included repeated items.

\section{EXPERIMENT 3}

In numerous studies with adults (e.g., Crowder, 1968; Greene, 1991; Henson, 1998a; Hinrichs, Mewaldt, \& Redding, 1973; Jahnke, 1969; Lee, 1976; Wickelgren, 1965) lists with repeated elements have been presented for serial recall, along with control lists that have not contained repetitions. Typically, a comparison has been made between recall of repeated pairs and recall of the corresponding pairs in the control lists. When the repeated elements are adjacent in the sequence, recall of the repeated pair is usually superior to recall of control items, a phenomenon labeled repetition facilitation. However, when there are a number of other list items separating repeated elements, recall is generally poorer for the repeated pair; that is, there is repetition inhibition or the Ranschburg effect.

Such a task potentially overcomes the possible explanation of the findings of Experiments 1 and 2 mentioned above (that the lack of a developmental decrease in repetition errors is a by-product of young children's failure to use the information that the lists were drawn from a fixed vocabulary). The measure of repetition inhibition is calculated by a within-subjects comparison of performance on control and repetition lists, and it could be argued that such a failure of understanding should affect both types of lists equally.

In Experiment 3, we used a procedure very similar to that of Experiments 1 and 2, except that a proportion of the lists contained repetitions. The other key difference was that phonologically nonconfusable items were used, in an attempt to avoid low levels of performance in the younger age groups which might mask the effects of interest. However, a pilot study found that an adult group (comprising 28 undergraduates) was close to ceiling on this task. Thus, the participants in this study were children in the age range used in Experiments 1 and 2.

\section{Method}

Participants. Sixty children participated in the study, 20 in each of three age groups: 7-year-olds ( $M=7.67$ years), 9-year-olds ( $M=9.53$ years), and 11-year-olds ( $M=11.33$ years). Children who participated in this study were predominantly Caucasian and of middle class.

Materials and design. The phonologically dissimilar letters J, H, M, Q, R, V were used to generate 18 six-item test lists, and a further 2 four-item and 2 six-item practice lists. Two thirds of the test lists contained repetitions, with 3 lists each of four repetition formats (repetition separations of 1, 2, 3, or 4). The remaining 6 test lists were control lists that did not contain any repetitions. Lists with a repetition separation of 1 contained an adjacent repeated pair (e.g., JHHMQR), those with a repetition separation of 2 had a repeated item two positions away from the first occurrence (e.g., JHMHQR), and so on. Due to the 
small number of lists that could be used with these age groups, it was not possible to vary the serial positions of the repeated pairs for each repetition format. Thus, the first item of each repeated pair always occurred in the second serial position.

The order of letters within each test list was randomized individually for every participant (subject to repetition lists containing repeated items in the appropriate serial positions), and the order in which each type of list appeared was also randomized with the constraint that no two examples of a repetition format appeared consecutively.

The stimuli in this task were letters printed on cards, with additional copies of each stimulus for use in lists with repetitions. Letters were presented by turning over the cards at a rate of approximately one per second. Presenting each stimulus on a separate card ensured that participants detected each stimulus (with VDU presentation it is possible to fail to notice the second occurrence of an item if it is immediately repeated).

Procedure. The procedure for administering the serial recall task was identical to that used in Experiment 2, except for the instructions regarding repetitions. Two of the lists used in the practice trials contained repetitions, and participants were explicitly told that some, but not all, of the test lists contained the same item twice.

\section{Results}

Analysis of repetition facilitation and inhibition. The mean delta values for all groups were calculated using Henson's modified control scoring system (see Henson, 1998a, for details). For a given repetition separation, the delta value is the difference between the probability of recalling both repeated items and the probability of recalling both control items. Thus, repetition facilitation gives a positive delta value (repeated pairs recalled better than control pairs), and repetition inhibition gives a negative delta value (repeated pairs recalled worse than control pairs). We can further distinguish between delta values calculated under item scoring and under position scoring. Delta values under position scoring are calculated using the probabilities of correctly recalling both items in their appropriate serial positions. Under item scoring, whether items have been recalled in the correct serial position is not considered: Delta values are calculated using the probabilities of both items appearing anywhere in the recalled list. Henson (1998a) has shown that levels of response inhibition and response facilitation are different under item scoring than under position scoring (see discussion below).

Figure 8 shows the delta values under item scoring for each age group as a function of repetition separation (i.e., the separation of the repeated items in the presented list). It can be seen that the two older age groups appear to show a moderate degree of repetition facilitation for adjacent items, whereas this is not the case for the youngest group. All groups appear to show repetition inhibition for all other separations. For the two older groups, repetition inhibition appears 


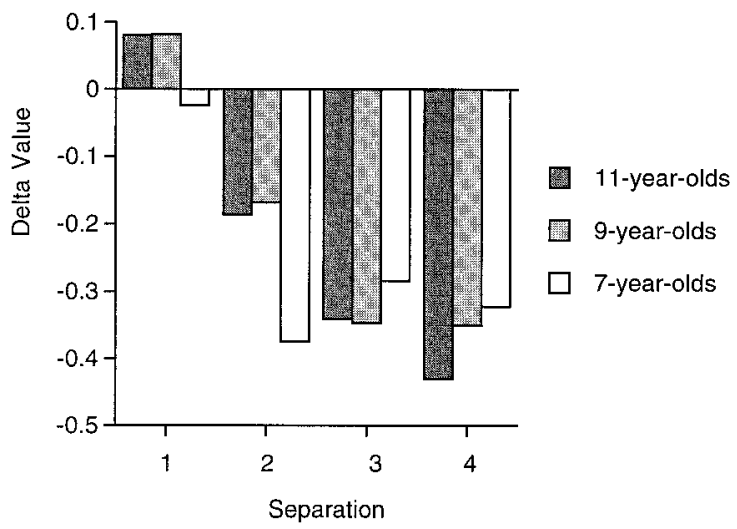

FIG. 8. Delta values as a function of age and separation under item scoring.

to increase with separation, whereas the 7-year-olds show the largest degree of repetition inhibition for a separation of 2. A two-way ANOVA on mean delta values with a between-subjects factor of age and a within-subjects factor of separation examined these trends. The main effect of age was not significant $[F<1]$, whereas the main effect of separation was significant $[F(3,171)=$ 20.46, $M S E=0.102, p<.01]$. The interaction between age and serial position did not reach significance $[F(6,171)=1.81, M S E=0.102, p=$ .32]. One-sample $t$ tests were used to examine the extent to which delta values differed from zero (i.e., the extent to which repetition facilitation and inhibition were significant). None of the groups showed significant repetition facilitation for adjacent repetitions, but repetition inhibition was significant for all groups at all other separations (a significance level of $p<.05$ was taken for these and subsequent comparisons).

Figure 9 shows the delta values under position scoring. It can be seen that all groups showed a large repetition facilitation effect for adjacent items. This effect appears to persist for the older two groups for a separation of 2, with repetition inhibition increasing at subsequent separations for these two groups. The 7-yearolds appear to have small and constant repetition inhibition across separations of 2, 3, and 4. An ANOVA on these delta values found no significant effect of age $[F(2,57)=1.28, M S E=0.143, p=.29]$. However, both the main effect of separation $[F(3,171)=23.87, M S E=0.105, p<.01]$ and the interaction between age and separation $[F(3,171)=2.73, M S E=0.105, p<.02]$ were significant. Analysis of simple effects showed that the effect of age was significant for a separation of 2 only $[F(2,57)=3.39, M S E=0.24, p<.05]$, with the two older groups having greater repetition facilitation than the 7-year-olds. One-sample $t$ tests found that all groups showed significant repetition facilitation for adjacent repetitions, but none of the groups showed significant facilitation for a separation of 2 (although $p$ values for this separation almost reached signifi- 


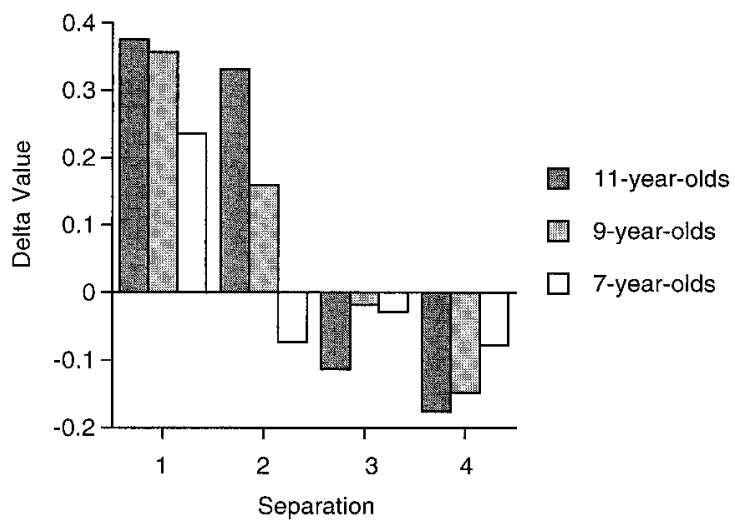

FIG. 9. Delta values as a function of age and separation under position scoring.

cance for the older two groups, $p<.08)$. Repetition inhibition was not significant for the 7-year-olds at any separations, but reached significance for the 9-year-olds for a separation of 4 , and for the 11-year-olds for separations of 3 and 4.

Analysis of repetition errors. For lists with repeated items, many of the errors cannot be classified using the categories employed in Experiments 1 and 2; therefore we report only analyses of repetition errors. For both list types, all age groups produced similar numbers of erroneous repetitions. Two ANOVAs on the number of erroneous repetitions (one for lists with repeated items and one for control lists) found no main effects of age on the number of repetitions $[F<1]$. For lists with repeated items, the mean separation of the repetition errors was 2.7 for each of the three age groups; thus, the effect of age was not significant $[F<$ 1]. The effect of age on average separation of the repetition errors made on control lists was also not significant $[F(2,52)=2.07, M S E=0.57, p=.14]$.

\section{Discussion}

Consistent with the findings of Experiments 1 and 2, there was no evidence for developmental increases in response inhibition. Under both item and position scoring, there were no significant developmental decreases in delta values. Further, there were no age-related changes in the number of erroneous repetitions.

Repetition facilitation. All age groups showed either small positive delta values or delta values close to zero for adjacent repetitions under item scoring. Importantly, the delta values for adjacent separations under item scoring did not change significantly with age. Coupled with the finding that all groups produced similar levels of erroneous repetitions, this result suggests that all age groups understood that they were able to give repetitions in their responses. The failure to find significant repetition facilitation under item scoring is consistent with the 
findings of Henson (1998a, Experiment 1), as is the contrasting finding of large positive delta values for adjacent items under position scoring. This contrast between item and position scoring suggests that better recall of adjacent repeated items is due to an increased probability of positioning them correctly, rather than an increased likelihood of recalling both items. Our data suggest that this benefit of repetition on position recall increases with age, since there was a significant age effect on the size of delta values under position scoring.

Although a variety of explanations of the repetition facilitation effect have been given (Lee, 1976; Wickelgren, 1965), we favor an account in terms of some special coding or tagging of repetitions which occur close together (Henson, 1998a; Houghton, Glasspool, \& Shallice, 1994). One way of explaining the facilitation effect is to assume that repetition tags are associated with particular list locations. Such tags facilitate the placing of repeated pairs in the correct list positions. The developmental increase in repetition facilitation found under position scoring (but not under item scoring) suggests that older children may be more efficient at tagging list locations in this way.

Repetition inhibition. There were no significant developmental changes in repetition inhibition, either under item scoring or under position scoring. Response inhibition was less marked under position scoring than under item scoring (see also Henson, 1998a). This suggests that response inhibition, in contrast to repetition facilitation, may primarily affect whether items are actually repeated, not whether they are placed in the correct positions. However, there are two competing hypotheses of why participants may fail to repeat items. We have assumed so far that such a failure reflects an automatic response suppression process, but it has been argued elsewhere that it reflects a guessing bias (e.g., Hinrichs, Mewaldt, \& Redding, 1973). According to the guessing hypothesis, participants are generally biased against giving the same item twice if they are unsure of their response and have to guess. It is possible that both a guessing bias and response inhibition may contribute to the effect (see Henson, 1998a, for an extensive review). Since overall performance improved with age, it is likely that there were age differences in the proportion of responses that were guesses. However, since we failed to find significant developmental changes in the amount of repetition inhibition, it is difficult to assess the impact of possible age changes in guessing levels. Further, the stability in the proportion of erroneous repetitions across age groups suggests that there were no developmental changes in the willingness of participants to include repetitions in their responses.

\section{GENERAL DISCUSSION}

The aim of the current study was to examine whether a detailed analysis of age-related changes in error patterns could shed light on the mechanisms underpinning development in STM. In addition to changes in overall levels of performance, we found developmental differences in the patterns of errors. First, in Experiment 1, there was a developmental increase with age in the proportion of 
errors that were repetitions and a decrease in the proportion of intrusions. There was a marginally significant trend for the proportion of errors that were movements to be greater in adults than in children. In Experiment 2, error proportions were examined in terms of their distribution across serial positions, and a significant developmental decrease was found in the relative proportions of omission to movement errors at later output serial positions. Second, in both Experiments 1 and 2, a developmental change was found in the nature of movement errors, with older children and adults being more likely than young children to place moved items close to their original serial positions. Lastly, in all three experiments, the absolute numbers of repetition errors did not decrease with age, in contrast to all other error types. Further, there was no evidence for developmental increases in the level of response inhibition as given by a comparison of recall of lists with and without repeated items (Experiment 3). The average separation of repetition errors also did not change with age. A complete account of STM development should be able to explain the patterns of changes found in the current study.

\section{Theories of STM Development}

Rehearsal-based accounts have not as yet been extended to explain age changes in the detailed characteristics of serial recall performance. However, it is possible that the onset of rehearsal or changes in its efficiency do affect such aspects of performance, although in the absence of a well-specified account of the relevant processes it is difficult to predict the impact of the development of rehearsal on error patterns.

A contrasting approach would be to assume that there are developmental changes in aspects of serial recall mechanisms. Changes in the steepness of movement gradients suggest that there are developmental improvements in the efficiency of the memory mechanisms responsible for the encoding and retrieval of serial order information. There are a number of models of such mechanisms which provide competing accounts of such processes (e.g., Brown et al., 2000; Burgess \& Hitch, 1999; Henson, 1998b; Henson \& Burgess, 1998; Lewandowsky \& Murdock, 1989; Page \& Norris, 1998). These models differ primarily in terms of the way in which they represent temporal order information. Although it may be possible to generate competing developmental versions of such models, it is likely that any such model would assume age changes in the accuracy of temporal encoding or retrieval processes in order to fit the current data. The data reported here provide a new domain in which such models can be tested, since a successful model should be able to capture the developmental patterns that we have found.

We favor a model that has been independently applied to a wide range of adult serial recall data, and that assumes it is possible to vary the distinctiveness of the temporal-contextual cues that are associated with each item (Brown et al., 2000). We have shown elsewhere that varying temporal distinctiveness in this way 
affects the steepness of the movement gradients in a manner similar to that observed in the data, and also affects the overall numbers of movement, omission, and intrusion errors (Brown et al., 1999; Maylor et al., 1999).

Could a temporal distinctiveness account explain the relatively large numbers of omission errors made by younger children at the later stages of recall? This finding suggests that there were greater levels of forgetting during output by such groups. Levels of output forgetting may be closely related to speed of output, and a variety of processes may change in their speed of operation with age (Kail, 1997; Kail \& Park, 1994); for example, younger children may produce their written responses more slowly, or may have slower memory search and retrieval processes (Cowan et al., 1992). However, some of the developmental changes in speed of output may in fact be a result of changes in temporal distinctiveness. This would be the case if the speed of memory search was determined by the distinctiveness of retrieval cues, with slower memory search then leading to more omissions at late serial positions. This suggestion can be contrasted with Cowan et al.'s (1998) claim that speed of search is determined by the efficiency of central executive processes. If the suggestion is correct, a single factor-temporal distinctiveness - may account not only for the observed changes in movement gradients but also for developmental differences in error patterns across output serial positions.

\section{The Inhibition Hypothesis}

We interpreted the failure to find developmental decreases in the number of repetition errors in terms of the developmental stability of the inhibitory process of response suppression, and this interpretation was supported using the measure most commonly used to examine this process in adults. However, although we have found no evidence of developmental changes in this inhibitory process, an alternative approach to inhibition and STM development might be to explore whether younger children are more susceptible to interference from previous lists or from task-irrelevant information (e.g., Dempster, 1992, 1993; Harnishfeger \& Bjorklund, 1993; Lorsbach \& Reimer, 1997; Wilson \& Kipp, 1998). Further, it could be argued that age changes in output forgetting are due to developmental differences in levels of output interference rather than speed of processing, if it is assumed that outputting each list item interferes with recall of subsequent items in the list (Brainerd, 1995; Brainerd \& Reyna, 1989).

The current study did not specifically address these issues, and it is clear that further research is necessary to examine the role played by these types of interference in determining STM performance. In our experiments, all lists contained the same items; thus we could not examine levels of intrusions from previous lists. However, we did examine developmental changes in the numbers of erroneously recalled extralist items. The developmental decline that we found in such errors is consistent with Harnishfeger and Bjorklund's claim that young children have difficulty excluding irrelevant information in memory tasks. 
It should be noted that it is possible to distinguish computationally between the processes that primarily determine levels of repetition errors and those that determine levels of intrusion errors. The postoutput response suppression process has a short time course, and on the basis of the pattern of repetition errors found in our studies, it can be assumed to wear off after two or three subsequent item recalls (see Fig. 7; see also Vousden \& Brown, 1998). In our own modeling work, the processes that determine levels of interference from longer term memory are assumed to be very different from that of postoutput response suppression (Brown et al., 1999, 2000), with intrusions primarily resulting from a failure to generate retrieval cues that are sufficiently distinctive to specify an item from the just-presented list. Therefore, it is quite possible that levels of interference change with development, while response suppression remains invariant.

\section{Development of Serial Recall across the Life Span}

Elsewhere, Maylor et al. (1999) have reported a similar analysis of the errors made by young and older adults in a serial recall task (although details of repetition errors were not reported). The similarities between the current findings and those of Maylor et al. are striking. Although changes in the movement gradients with age were much less marked than in the current study, older adults did have significantly more shallow gradients. There was a similar interaction between age and the proportion of movement to omission errors over output serial position, with older adults being more likely to omit items at later serial positions. Further, a reanalysis of the Maylor et al. data has found that if young adults are divided into groups on the basis of their IQ scores, similar group differences in error patterns are observed (Maylor, personal communication, 1998). The similarities between the developmental effects found in the current study and those found in the Maylor et al. (1999) study suggest that it is implausible to account for our findings in terms of changes that might be specific to development in childhood. On the basis of currently available data, it appears that there are certain error patterns that are generally associated with lower levels of performance rather than specific to any particular group.

However, although we have found developmental changes in STM that are similar at both ends of the life span, we note that the youngest participants in our study were 7-year-olds. It is normally assumed that the most pronounced changes in the use of strategies such as rehearsal occur between 5 and 7 years, and it is possible that children younger than 7 use qualitatively different strategies and would show very different patterns of errors. Unfortunately, the written serial recall technique cannot be used with such young children. However, we have shown that the technique can be used with the age range considered in the current study, and that it provides a rich source of data which theories of short-term memory development need to account for. In particular, the detailed analyses of errors that we have reported are consistent with models of serial recall development that emphasize output processes and the development of increasingly 
distinctive positional or temporal cues for encoding and retrieving serial order information. The results did not support any inhibitory hypothesis which would accord a role to the development of the post-output inhibitory response suppression processes that are incorporated into most recent models of adult serial recall.

\section{REFERENCES}

Berch, D. B. (1979). Coding of spatial and temporal information in episodic memory. Advances in Child Development and Behaviour, 13, 1-42.

Brainerd, C. J. (1995). Interference processes in memory development: The case of cognitive triage. In F. N. Dempster \& C. J. Brainerd (Eds.), Interference and inhibition in cognition (pp. 108-139). San Diego: Academic Press.

Brainerd, C. J., \& Reyna, V. F. (1989). Output-interference theory of dual-task deficits in memory development. Journal of Experimental Child Psychology, 47, 1-18.

Brown, G. D. A., \& Hulme, C. (1995). Modeling item length effects in memory span: No rehearsal needed? Journal of Memory and Language, 34, 594-621.

Brown, G. D. A., Preece, T., \& Hulme, C. (2000). Oscillator-based memory for serial order. Psychological Review, 107, 127-181.

Brown, G. D. A., \& Vousden, J. I. (1998). Adaptive sequential behavior: Oscillators as rational mechanisms. In M. Oaksford \& N. Chater (Eds.), Rational models of cognition (pp. 165-193). Oxford: Oxford Univ. Press.

Brown, G. D. A., Vousden, J. I., McCormack, T., \& Hulme, C. (1999). The development of memory for serial order: A temporal contextual distinctiveness model. International Journal of Psychology, 34, 389-402.

Burgess, N., \& Hitch, G. J. (1992). Towards a network model of the articulatory loop. Journal of Memory and Language, 31, 429-460.

Burgess, N., \& Hitch, G. J. (1999). Memory for serial order: A network model of the phonological loop and its timing. Psychological Review, 106, 551-581.

Conrad, R. (1965). Order errors in immediate recall of sequences. Journal of Verbal Learning and Verbal Behavior, 4, 161-169.

Cowan, N., Day, L., Saults, J. S., Keller, A. T., Johnson, T., \& Flores, L. (1992). The role of verbal output time in the effects of word length on immediate memory. Journal of Memory and Language, 31, 1-17.

Cowan, N., \& Kail, R. (1996). Covert processes and their development in short-term memory. In S. E. Gathercole (Ed.), Models of short-term memory (pp. 29-50). Hove, UK: Psychology Press.

Cowan, N., Wood, N. L., Nugent, L. D., \& Treisman, M. (1997). There are two word-length effects in verbal short-term memory: Opposed effects of duration and complexity. Psychological Science, 8, 290-295.

Cowan, N., Wood, N. L., Wood, P. K., Keller, T. A., Nugent, L. D., \& Keller, C. V. (1998). Two separate verbal processing rates contributing to short-term memory span. Journal of Experimental Psychology: General, 127, 141-160.

Crowder, R. G. (1968). Interserial repetition effects in immediate memory. Journal of Verbal Learning and Verbal Behavior, 7, 446-451.

Dell, G. S., Burger, L. K., \& Svec, W. (1997). Language production and serial order: A functional analysis and a model. Psychological Review, 104, 123-147.

Dempster, F. N. (1992). The rise and fall of the inhibitory mechanism: Towards a unified theory of cognitive development and aging. Developmental Review, 12, 45-75.

Dempster, F. N. (1993). Resistance to interference: Developmental changes in a basic processing mechanism. In M. L. Howe \& R. Pasnak (Eds.), Emerging themes in cognitive development: Vol. 1. Foundations (pp. 3-27). New York: Springer-Verlag.

Diamond, A. (1991). Guidelines for the study of brain-behaviour relationships during development. 
In H. S. Levin, H. M. Eisenberg, \& A. L. Benton (Eds.), Frontal lobe function and dysfunction (pp. 339-377). Oxford: Oxford Univ. Press.

Dunn, L. M., Dunn, L. M., Whetton, C., \& Pintilie, D. (1982). The British Picture Vocabulary Scale. Windsor, UK: NFER-NELSON.

Gathercole, S. E., \& Hitch, G. J. (1993). Developmental changes in short-term memory: A revised working memory hypothesis. In A. F. Collins, S. E. Gathercole, M. A. Conway, \& P. E. Morris (Eds.), Theories of memory. Hove, UK: Erlbaum.

Glenberg, A. M. (1987). Temporal context and recency. In D. S. Gorfein \& R. R. Hoffman (Eds.), Memory and learning: The Ebbinghaus Centennial Conference (pp. 173-190). Hillsdale, NJ: Erlbaum.

Glenberg, A. M., \& Swanson, N. G. (1986). A temporal distinctiveness theory of recency and modality effects. Journal of Experimental Psychology: Learning, Memory, and Cognition, 15, $266-274$.

Greene, R. L. (1991). The Ranschburg effect: The role of guessing strategies. Memory \& Cognition, 19, 313-317.

Harnishfeger, K. K. (1995). The development of cognitive inhibition: Theories, definitions and research evidence. In F. N. Dempster \& C. J. Brainerd (Eds.), Interference and inhibition in cognition (pp. 176-204). San Diego: Academic Press.

Harnishfeger, K. K., \& Bjorklund, D. F. (1993). The ontogeny of inhibition mechanisms: A renewed approach to cognitive development. In M. L. Howe \& R. Pasnak (Eds.), Emerging themes in cognitive development: Vol. 1. Foundations (pp. 28-49). New York: Springer-Verlag.

Harnishfeger, K. K., \& Pope, R. S. (1996). Intending to forget: The development of cognitive inhibition in directed forgetting. Journal of Experimental Child Psychology, 62, 292-315.

Hartley, T., \& Houghton, G. (1996). A linguistically constrained model of short-term memory for nonwords. Journal of Memory and Language, 35, 1-31.

Hasher, L., Stoltzfus, E. R., Zacks, R. T., \& Rypma, B. (1991). Age and inhibition. Journal of Experimental Psychology: Learning, Memory, and Cognition, 17, 163-169.

Healy, A. F., Cunningham, T. F., Gesi, A. T., Till, R. G., \& Bourne, L. E. (1991). Comparing short-term recall of item, temporal, and spatial information in children and adults. In W. E. Hockley \& S. Lewandowsky (Eds.), Relating theory and data: Essays on human memory in honor of Bennet B. Murdock (pp. 127-154). Hillsdale, NJ: Erlbaum.

Henry, L. A. (1991). The effects of word length and phonemic similarity in young children's short-term memory. Quarterly Journal of Experimental Psychology, 43A, 35-52.

Henry, L. A., \& Miller, S. (1993). Why does memory span improve with age? A review of evidence for two current hypotheses. European Journal of Cognitive Psychology, 5, 241-287.

Henson, R. N. A. (1996). Short-term memory for serial order. Unpublished doctoral dissertation, University of Cambridge, Cambridge, UK.

Henson, R. N. A. (1998a). Item repetition in short-term memory: Ranschburg repeated. Journal of Experimental Psychology: Learning, Memory, and Cognition, 24, 1162-1181.

Henson, R. N. A. (1998b). Short-term memory for serial order: The Start-End Model. Cognitive Psychology, 36, 73-137.

Henson, R. N. A., \& Burgess, N. (1998). Representations of serial order. In J. A. Bullinaria, D. W. Glasspool, \& G. Houghton (Eds.), 4th Neural Computation and Psychology Workshop (pp. 283-300). London: Springer.

Henson, R. N. A., Norris, D. G., Page, M. P. A., \& Baddeley, A. D. (1996). Unchained memory: Error patterns rule out chaining models of immediate serial recall. Quarterly Journal of Experimental Psychology, 49A, 80-115.

Hinrichs, J. V., Mewaldt, S. P., \& Redding, J. (1973). The repetition effect: Repetition and guessing factors in short-term memory. Journal of Verbal Learning and Verbal Behavior, 12, 64-75.

Hitch, G. J., Halliday, M. S., Dodd, A., \& Littler, J. E. (1989). Development of rehearsal in short-term memory: Differences between pictorial and spoken stimuli. British Journal of Developmental Psychology, 7, 347-362. 
Hitch, G. J., Halliday, M. S., Schaafstal, A. M., \& Heffernan, T. M. (1991). Speech, "inner speech," and the development of short-term memory: Effects of picture-labelling on recall. Journal of Experimental Child Psychology, 51, 220-234.

Houghton, G. (1990). The problem of serial order: A neural network model of sequence learning and recall. In R. Dale, C. Mellish, \& M. Zock, (Eds.), Current research in natural language generation (pp. 287-319). London: Academic Press.

Houghton, G. (1994). Inhibitory control of neurodynamics: Opponent mechanisms in sequencing and selective attention. In M. Oaksford \& G. D. A. Brown (Eds.), Neurodynamics and psychology (pp. 107-155). London: Academic Press.

Houghton, G., Glasspool, G. W., \& Shallice, T. (1994). Spelling and serial recall: Insights from a competitive queuing model. In G. D. A. Brown \& N. C. Ellis (Eds.), Handbook of spelling (pp. 365-404). Chichester, UK: Wiley.

Hulme, C., Silvester, J., Smith, S., \& Muir, C. (1986). The effects of word length on memory for pictures: Evidence for speech coding in young children. Journal of Experimental Child Psychology, 41, 61-75.

Hulme, C., \& Tordoff, V. (1989). Working memory development: The effects of speech rate, word length, and acoustic similarity on serial recall. Journal of Experimental Child Psychology, 47, $72-87$.

Jahnke, J. C. (1969). The Ranschburg effect. Psychological Review, 76, 592-605.

Jahnke, J. C., \& Bower, R. E. (1986). Are there two Ranschburg effects? American Journal of Psychology, 99, 275-288.

Kail, R. (1997). Phonological skill and articulation time independently contribute to the development of memory span. Journal of Experimental Child Psychology, 67, 57-68.

Kail, R., \& Park, Y. S. (1994). Processing time, articulation time, and memory span. Journal of Experimental Child Psychology, 57, 281-291.

Lee, C. L. (1976). Short-term recall of repeated items and detection of repetitions in letter sequences. Journal of Experimental Psychology: Learning, Memory, and Cognition, 2, 120-127.

Lee, C. L., \& Estes, W. K. (1981). Item and order information in short-term memory: Evidence for multilevel perturbation processes. Journal of Experimental Psychology: Human Learning and Memory, 7, 149-169.

Lewandowsky, S. (1999). Redintegration and response suppression in serial recall: A dynamic network model. International Journal of Psychology, 34, 434-446.

Lewandowsky, S., \& Farrell, S. (in press). A redintegration account of the effect of speech rate, lexicality, and word frequency in immediate serial recall. Psychological Research.

Lewandowsky, S., \& Murdock, B. B. (1989). Memory for serial order. Psychological Review, 96, 25-57.

Lorsbach, T. C., \& Reimer, J. F. (1997). Developmental changes in the inhibition of previously irrelevant information. Journal of Experimental Child Psychology, 64, 317-342.

Maylor, E. A., Vousden, J. I., \& Brown, G. D. A. (1999). Adult age differences in short-term memory for serial order: Data and a model. Psychology and Aging, 14, 572-594.

Murray, D. J. (1968). Articulation and acoustic confusability in short-term memory. Journal of Experimental Psychology, 78, 679-684.

Nairne, J. S. (1992). The loss of positional certainty in long-term memory. Psychological Science, 3, 199-202.

Neath, I. (1993a). Contextual and distinctive processes and the serial position functions. Journal of Memory and Language, 32, 820-840.

Neath, I. (1993b). Distinctiveness and serial position effects in recognition. Memory \& Cognition, 21, $689-658$.

Neath, I., \& Crowder, R. G. (1990). Schedules of presentation and temporal distinctiveness in human memory. Journal of Experimental Psychology: Learning, Memory and Cognition, 16, 316-327.

Neath, I., \& Crowder, R. G. (1996). Distinctiveness and very short-term serial position effects. Memory, 4, 225-242. 
Neath, I., \& Nairne, J. S. (1995). Word-length effects in immediate memory: Overwriting trace decay theory. Psychonomic Bulletin \& Review, 2, 429-441.

Page, M. P. A., \& Norris, D. (1998). The primacy model: A new model of immediate serial recall. Psychological Review, 105, 761-781.

Pickering, S. J., Gathercole, S. E., \& Peaker, S. M. (1998). Verbal and visuospatial short-term memory in children: Evidence for common and distinct mechanisms. Memory \& Cognition, 26, $1117-1130$.

Roodenrys, S., Hulme, C., \& Brown, G. D. A. (1993). The development of short-term memory span: Separable effects of speech rate and long-term memory. Journal of Experimental Child Psychology, 56, 431-442.

Tipper, S. P., Bourque, T. A., Anderson, S. H., \& Brehaut, J. C. (1989). Mechanisms of attention: A developmental study. Journal of Experimental Child Psychology, 48, 353-378.

Vousden, J., \& Brown, G. D. A. (1998). To repeat or not to repeat: The time course of response suppression in sequential behaviour. In J. A. Bullinaria, D. W. Glasspool, \& G. Houghton (Eds.), Proceedings of the Fourth Neural Computation and Psychology Workshop: Connectionist representations (pp. 301-315). London: Springer-Verlag.

Wickelgren, W. A. (1965). Short-term memory for repeated and non-repeated items. Quarterly Journal of Experimental Psychology, 17, 14-25.

Wilson, S. P., \& Kipp, K. (1998). The development of efficient inhibition: Evidence from directedforgetting tasks. Developmental Review, 18, 86-123.

Received March 2, 1999; revised October 19, 1999 